\title{
Improved Efficiency of Heat Exchange Using KELEA Activated Water
}

\author{
W. John Martin \\ Institute of Progressive Medicine, South Pasadena, USA \\ Email: wjohnmartin@ccid.org
}

Received 10 May 2015; accepted 9 June 2015; published 12 June 2015

Copyright (C) 2015 by author and Scientific Research Publishing Inc.

This work is licensed under the Creative Commons Attribution International License (CC BY). http://creativecommons.org/licenses/by/4.0/

(c) (i) Open Access

\section{Abstract}

An environmental force termed KELEA (kinetic energy limiting electrostatic attraction) is postulated to reduce the strength of intermolecular (hydrogen) bonding of water molecules, resulting in increased kinetic activity of the water. While regular water does not directly absorb KELEA from the environment, various dipolar compounds with separated electrical charges can seemingly act as a primary antenna for KELEA, with secondary transfer of energy into nearby water. Moreover, once sufficiently activated, the separated electrical charges in activated water can apparently function as a receiver for KELEA, leading to further activation of the water and also to the activation of added water. Prior publications have addressed the agricultural and potential clinical benefits of using KELEA activated water. This article is intended as the first in a series of papers describing useful industrial applications of KELEA activated water. The focus of the present paper is on the improved efficiency of industrial water heating and cooling systems by using KELEA activated water provided by pelleted, ground and heated volcanic rock as supplied by Kiko Technology.

\section{Keywords}

KELEA, Kinetic Energy Limiting Electrostatic Attraction, Kiko Technology, Heat Exchange, Volcanic Rock, Refrigeration, Water Cooling Tower

\section{Introduction}

Devices, which allow for the transfer heat from hot to colder fluids, are widely used in residences, industries and transportation. This paper describes a relatively simple approach to increasing the efficiency of heat transfer to water in two major industrial applications.

The production of chilled water in commercial buildings is commonly achieved using large refrigeration units 
termed chillers [1]. The basic components of a chiller are the condenser (compressor) and the evaporator. The condenser uses high-pressure compression to liquefy (condense) refrigerant vapor in a heat generating process. The evaporator allows the refrigerant liquid to re-vaporize, thereby, withdrawing heat from the local environment. The heat generated within the condenser is absorbed by water in a piped system, which typically transfers the heated water to a cooling tower, where the water loses heat to circulating air. The air-cooled water is recirculated back to the condenser, in a continuing process of lowering the heat of the condenser. The efficiency of the condenser cooling system is determined by heat of the condensed fluid, along with the extent that the circulating water leaving the condenser approaches the high temperature of the liquid refrigerant. The latter is referred to as the condenser's Approach Temperature Difference (ATD) or alternatively as the Small Temperature Difference (STD).

The heating of buildings in cold climates is typically achieved by passing steam through a well-insulated outer pipe, within which there is a segment of a continuing piping system that recirculates hot water throughout the building. The steam driven heating unit is called a heat exchanger [2]. The efficiency of the heat exchanger is measured in terms of both the amount of steam utilized, (expressed as pounds, "lbs" of liquid water equivalence), and the temperature differences between the water entering and existing the heat exchanger.

A major factor limiting the long-term efficiency of heat transfer in condensers and in heat exchangers is narrowing of the effective diameters of the water pipes. This can be due to chemical corrosion (primarily oxidation) of metal pipes and/or to the precipitation of calcium and magnesium carbonates, silica and other deposits, as scales onto the inner surface of the pipes. The corrosion and scaling processes are differentially influenced by the $\mathrm{pH}$ of the water, the buffering capacity of the water (expressed as alkalinity) and by the concentration of calcium, magnesium, silica and other minerals [3].

Various methods have been reported to reduce scale formation within water pipes [4]. While most rely upon the addition of reactive chemicals, some are based upon inducing a physical change in the "structuring" of water. For example, the vortexing of water or placing water pipes within a magnetic field has been shown to reduce the scale-forming capacity of water [5]-[11]. Applying alternating electromagnetic current, electrolysis or fixed electrostatic charge is also reported to be effective, especially in limiting the particle size and the pipe-attaching property of precipitated calcium carbonate [12] [13]. Certain compounds added to water may also alter physical, as opposed to chemical, properties of the water in a manner similar to that achieved by vortexing, magnets and electrical charges. Examples include humic and fulvic acids [14] [15], zeolites [16], certain ceramics [17], mica, ground volcanic rock and various synthetic polymers [14]. Physical energy based anti-scaling devices are being marketed on the Internet [18] [19], including reported benefits from simply passing regular water nearby to physically "activated" water [20]. The various marketed devices have yet to find widespread applications in major industries utilizing heat exchange technology.

Pellets formed from ground and heated volcanic rocks can be placed within cartridges that have small holes to allow water to make contact with the pellets. These cartridges are commercially available from Kiko Technology Inc. (www.kikotechnology.com). As reported elsewhere, the placement of 5 Kiko cartridges per hectare can significantly enhance the agricultural productivity of rice, sugarcane and other crops [21]. This paper reports that Kiko cartridges can also be used in heat transfer equipment. Not only do they delay the formation of scale within water pipes, but additionally add to the efficiency of heat transfer to water. The two industrial systems studied are 1) heat loss from the condenser of a chiller and 2) the heating of water by a heat exchanger.

\section{Methods}

The Kiko cartridges used were similar to those described in the agricultural studies, except that steel rather than polypropylene casing cartridges were used in the heat exchanger system. The cartridges measure $20 \mathrm{~mm} \times 128$ mm with multiple $2 \mathrm{~mm}$ perforations and contain $\sim 50$ pellets of ground, heated volcanic rock from Japan. The cartridges were placed in a fixed location within the circulating water systems allowing for easy removal.

The condenser heat removal studies were conducted in the Canton Tower, China's second tallest building, located in Guangzhou, China. This 600 meter tall tower was constructed in 2010. The HVAC (heating, ventilation, air conditioning system) comprised 4 chillers, each connected to a separate cooling tower. Kiko cartridges were installed into the chillers primarily to delay scale formation, as assessed by visual inspection. ATD (STD) data on the chillers were obtained prior to and after instillation of Kiko cartridges.

The water heating study was conducted in Canada. An office building situated in Pender Street, Vancouver, 
Canada provides recirculating hot water for its tenants. Its heat exchanger is driven by steam generated by Creative Energy Vancouver Platforms Ltd., the major supplier of steam in Vancouver. A test protocol was established prior to the instillation of six Kiko cartridges into the piped water system. It comprised turning off the steam supply to allow the water temperature to fall below the normal operating level of between $63^{\circ} \mathrm{C}$ to $65^{\circ} \mathrm{C}$. The steam was then provided at 105 lbs per square inch (PSIG) to the heat exchanger. The rise in water temperature of the water leaving the heat exchanger was measured at half-minute intervals over the next 6.5 minutes. Other collected data included monthly steam utilization before and after installing Kiko technology.

\section{Results}

The refrigeration system in the Canton Tower began operating in May 2010 and continued to be operated till November 2010. The system comprised 4 chillers, each with its own cooling tower. The chillers were not operated through the winter months of 2011. Upon restarting on the $17^{\text {th }}$ May 2011, the ATD measurements of the condensers were at an unacceptably high level of $>5^{\circ} \mathrm{C}$, indicating a severe reduction in heat exchange efficiency. Moreover, upon opening the condensers for inspection in July 2011, severe scaling and rust were discovered on the inner surfaces of the water carrying tubes. This necessitated acid cleaning. The cleaning was not completely effective leaving a small amount of observable scale. Four Kiko cartridges per chiller were installed in the water line from the chiller to the water tower, with an additional 4 Kiko cartridges installed in the cooling tower. Instillation of the cartridges was primarily with the intention of preventing further scale formation. This proved to be so since no additional scale was seen in subsequent inspections over the next 9 months. Moreover, the minimal residual scaling following the July 2011 acid cleaning was noticeably becoming less at each inspection. Essentially, no scale was detected within the tubes during the March $2^{\text {nd }}, 2012$ inspection (Figure 1).

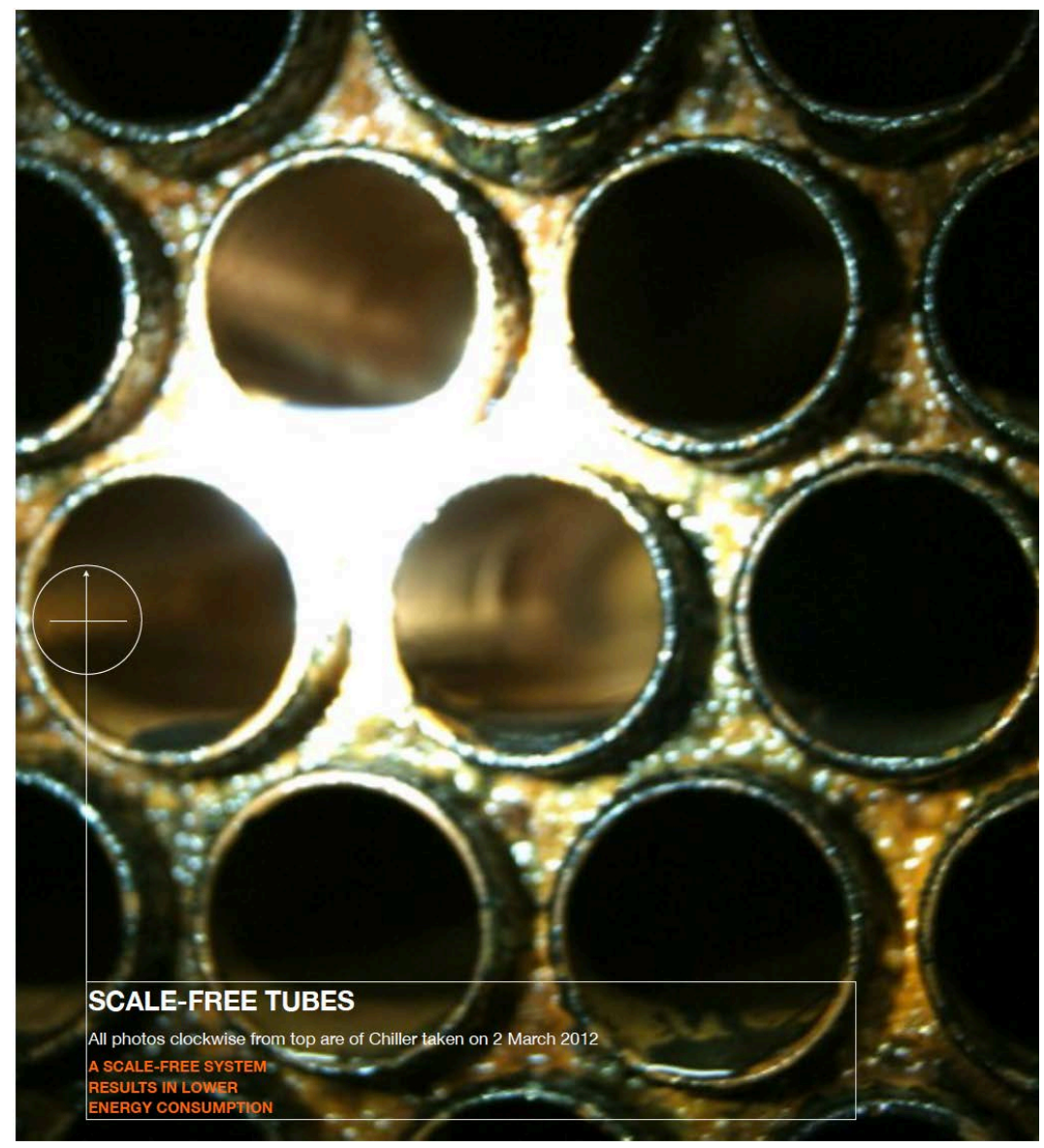

Figure 1. Magnified photograph taken on March 2, 2012 of series of 1" diameter water pipes within the condenser. The photo shows the lack of any scale formation or corrosion within the pipes. 
The ATD, that is the extent to which the temperature of the condensed liquid refrigerant exceeds the temperature of the water exiting the condenser, was monitored to assess the efficiency of heat removal from the condenser. As noted above, the 5/17/2011 value exceeded the acceptable upper limit of $5^{\circ} \mathrm{C}$. Within several weeks of installing the Kiko cartridges, the ATD had fallen. Table 1 records the improved ATD on 10/17/2011 and on $3 / 2 / 2012$ on one of the condensers. The $<1^{\circ} \mathrm{C}$ value observed on the $3 / 2 / 2012$ indicated excellent efficiency of heat dissipation from the condenser. Moreover, the temperature of the liquid refrigerant was being maintained at a lower temperature by the recirculating water $\left(32.9^{\circ} \mathrm{C}\right.$ compared $37^{\circ} \mathrm{C}$ on $\left.10 / 17 / 2011\right)$, again indicating improved efficiency of heat dissipation.

Heating: The rise in water temperature provided by steam delivery to the heat exchanger in the office building was monitored at 30-second intervals over the ensuring 6.5 minutes. The testing was performed on 3 occasions. The first testing was on December 20, 2013, just prior to installing Kiko cartridges. The next testing was conducted two months later on February 25, 2014. A third test was performed on March 28, 2014. A comparison of the data obtained on the 3 time points are recorded in Table 2 and shown graphically in Figure 2.

The recirculating hot water moves through small column filters intended to remove circulating rust and other debris released from the pipes. The filters clog over time and need to be periodically replaced with new filters. After installing Kiko cartridges, the replaced filters were noted to have progressively far less discoloration than previously. Reduced scale formation was also noted on the metal cap, which needed to be unscrewed to retrieve the filters.

In addition to steam being used by the heat exchanger for the production of hot water, the office building also received steam that was supplied directly to a series of radiators. By turning off the steam supply to the radiators, it was determined that the heat exchanger consumed approximately $75 \%$ of the total steam supplied to the building. With the exception of February, the monthly total steam consumption in 2014 was less than that of 2013 by 945,000 lbs. of steam (Table 3). This represents 21\% reduction. Given that the steam radiators

Table 1. Improved efficiency of heat removal from condenser after instillation of Kiko cartridges.

\begin{tabular}{cccc}
\hline Date & $\begin{array}{c}\text { Temp. of water from } \\
\text { condenser }\left({ }^{\circ} \mathrm{C}\right)\end{array}$ & $\begin{array}{c}\text { Temp. of refrigerant in } \\
\text { condenser }\left({ }^{\circ} \mathrm{C}\right)\end{array}$ & $\begin{array}{c}\text { Approach temp. } \\
\text { difference }(\mathrm{ATD})\left({ }^{\circ} \mathrm{C}\right)\end{array}$ \\
\hline $5-17-2011$ & 31.0 & 36.6 & 5.6 \\
$10-17-2011$ & 34.2 & 37.0 & 2.8 \\
$3-2-2012$ & 32.0 & 32.9 & 0.9 \\
\hline
\end{tabular}

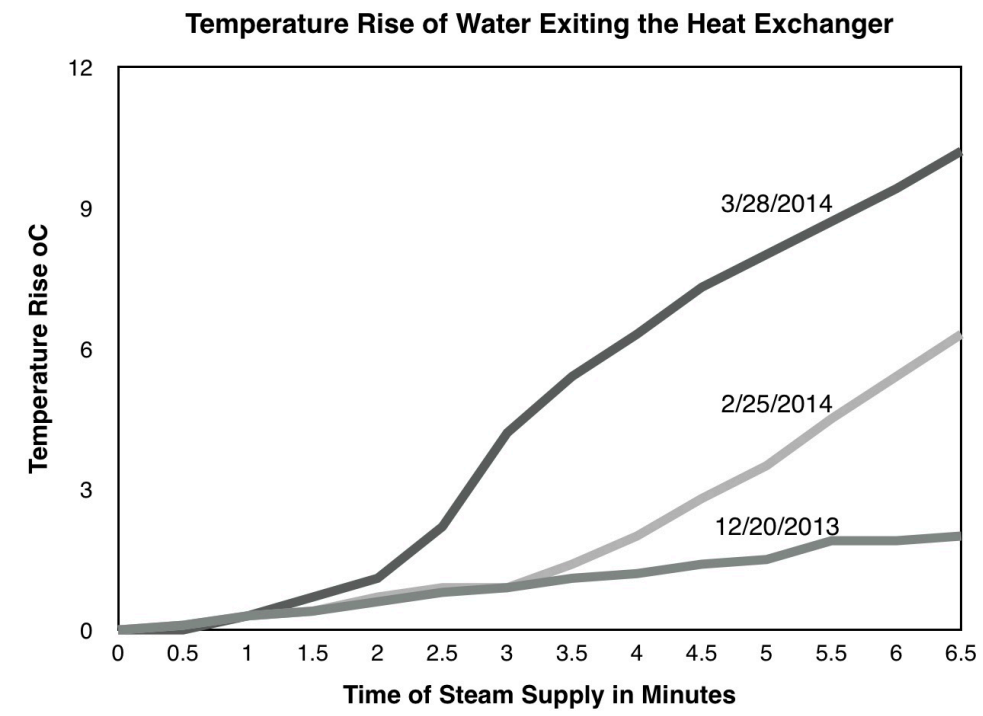

Figure 2. Measured aggregate increase in water temperature beyond the starting level, over a 6.5 minute period upon turning on the steam to the heat exchanger. 
Table 2. Improved efficiency of heat transfer in tests conducted prior to and at one and two months after the $20^{\text {th }}$ December instillation of Kiko cartridges in a heat exchanger supplying hot water to an office building.

\begin{tabular}{|c|c|c|c|c|c|c|}
\hline \multirow{2}{*}{$\begin{array}{l}\text { Time after } \\
\text { turning on } \\
\text { steam (min) }\end{array}$} & \multicolumn{2}{|c|}{ December 20, 2013} & \multicolumn{2}{|c|}{ February 25, 2014} & \multicolumn{2}{|c|}{ March 28, 2014} \\
\hline & Temp. ${ }^{\circ} \mathrm{C}$ & Rise ${ }^{\circ} \mathrm{C}$ & Temp. ${ }^{\circ} \mathrm{C}$ & Rise ${ }^{\circ} \mathrm{C}$ & Temp. ${ }^{\circ} \mathrm{C}$ & Rise ${ }^{\circ} \mathrm{C}$ \\
\hline 0.0 & 44.5 & - & 46.5 & - & 36.8 & - \\
\hline 0.5 & 44.6 & 0.1 & 46.6 & 0.1 & 36.8 & 0.0 \\
\hline 1.0 & 44.8 & 0.3 & 46.8 & 0.3 & 37.1 & 0.3 \\
\hline 1.5 & 44.9 & 0.4 & 46.9 & 0.4 & 37.5 & 0.7 \\
\hline 2.0 & 45.1 & 0.6 & 47.2 & 0.7 & 37.9 & 1.1 \\
\hline 2.5 & 45.3 & 0.8 & 47.4 & 0.9 & 39.0 & 2.2 \\
\hline 3.0 & 45.4 & 0.9 & 47.4 & 0.9 & 41.0 & 4.2 \\
\hline 3.5 & 45.6 & 1.1 & 47.9 & 1.4 & 42.2 & 5.4 \\
\hline 4.0 & 45.7 & 1.2 & 48.5 & 2.0 & 43.1 & 6.3 \\
\hline 4.5 & 45.9 & 1.4 & 49.3 & 2.8 & 44.1 & 7.3 \\
\hline 5.0 & 46.0 & 1.5 & 50.0 & 3.5 & 44.8 & 8.0 \\
\hline 5.5 & 46.4 & 1.9 & 51.0 & 4.5 & 45.5 & 8.7 \\
\hline 6.0 & 46.4 & 1.9 & 51.9 & 5.4 & 46.2 & 9.4 \\
\hline 6.5 & 46.5 & 2.0 & 52.8 & 6.3 & 47.0 & 10.2 \\
\hline
\end{tabular}

Table 3. Comparison of monthly steam consumption (in thousands of Lbs.) prior to and following instillation of Kiko cartridges on December 20, 2013.

\begin{tabular}{|c|c|c|c|}
\hline Month & 2013 consumption & 2014 consumption & Reduced consumption \\
\hline January & 833 & 620 & +213 \\
\hline February & 596 & $743^{*}$ & -147 \\
\hline March & 752 & 493 & +259 \\
\hline April & 382 & 319 & +63 \\
\hline May & 213 & 118 & +95 \\
\hline June & 147 & 87 & +60 \\
\hline July & $0 \dagger$ & 23 & -23 \\
\hline August & $0 \dagger$ & $0 \dagger$ & 0 \\
\hline September & 99 & 29 & +70 \\
\hline October & 275 & 210 & +65 \\
\hline November & 435 & 315 & +138 \\
\hline December & 707 & 555 & +152 \\
\hline Total & 4,457 & 3,512 & +945 \\
\hline
\end{tabular}

*The reason for the increased usage in February has not been determined, but may have involved increased usage of steam radiators, rather than of the heat exchanger. ${ }^{\dagger}$ System turned off. The steam consumption value for January 2015 was 600 confirming the continuing fuel saving.

consummed approximately $25 \%$ of total steam usage, the percentage reduction of steam provided to the heat exchanger is estimated to be around $28 \%$, a very substantial saving. 


\section{Discussion}

The concept that water molecules can differ in physical properties in ways unrelated to temperature, $\mathrm{pH}$ and the presence of other components within the water, has yet to be generally accepted within the scientific community. A limiting factor has been the lack of a unifying hypothesis to scientifically explain the basis for differences between regular water and what is commonly called "activated" water. In a major development, the author has described a natural water activation process that appears to involve the absorption of an environmental force termed KELEA (kinetic energy limiting electrostatic attraction). This force weakens intermolecular hydrogen bonding and contributes to the micro-streaming kinetic activity, which is readily observable in activated water. This effect is reflected in increased volatility, which can be quantitatively measured as the rate and extent of weight loss in closed but not completely sealed containers [22].

KELEA activation of water can be achieved by either adding various compounds to the water or by subjecting the water to different types of external energies. Many of the added compounds have separated electrical charges, as in dipolar and multipolar complexes. Examples include humic and fulvic acids, zeolites, mica, ground volcanic rocks, shungite (a product from Russia) and magnesium oxide. Heating products during manufacturing to high temperatures (e.g. $1000^{\circ} \mathrm{C}-1500^{\circ} \mathrm{C}$ ) increases their water activating activity. When used as pellets, very little of the material actually disperses within the water and any such dispensed material can be easily removed from the water by filtration. The remaining water maintains its activation and, indeed if sufficiently activated can become further activated over time; especially if maintained in completely sealed containers.

The observable changes in activated water include increased volatility, lowered viscosity, decreased surface tension, linear to-and-fro patterns of movements of sprinkled dyes, such as neutral red, and more rapid heating and cooling [22]. The Specific Heat of water, that is the amount of heat required to raise its temperature, is higher for water than for most other substances [23]. This is explained by a higher percentage of the applied thermal energy being consumed as increase rates of reversible intermolecular hydrogen bonding compared to heat emitting molecular vibrations. A lowered Specific Heat capacity for activated water can, therefore, be anticipated from the proposed KELEA loosening of intermolecular hydrogen bonding.

As mentioned in the introduction, activated water has been frequently suggested as a means to reduce scaling within water pipes [5]-[20]. Scaling can be a major problem as was demonstrated in the Canton Tower's chillers, prior to the installation of Kiko cartridges. A beneficial effect with regards to reduced scale formation was clearly achieved. Moreover, the minimal remaining scale following acid treatment of the water pipes was further reduced over time, consistent with the detachment of scale from pipes. This may be explained by reduced electrostatic attraction between the scale (mainly calcium carbonate) and the metal surface as a direct effect of KELEA. The larger particles of scale may dissociate into finer particles through a reduction of ionic bonding.

What was not expected from the instillation of Kiko Technology was the continued improvement of heat removal from the condenser between October 2011 and March 2012. Added improvement was similarly observed between February 2014 and March 2014 in the performance of the heat exchanger in the office building. While still possibly explainable on the basis of continuing removal of scale, it is more likely to reflect a continuing KELEA activation of the water and a lowering of its Specific Heat capacity. Testing using industrial water systems with non-metallic pipes, through which purified water is recirculating will allow for direct testing of the heat absorbing activity of water in the absence of either scale formation or metal corrosion. Whatever is the relative contribution of an increased kinetic activity of the water versus reduced scale formation and corrosion in the pipes, the major message of this report is the significant cost saving in fuel and energy expenditures that can be achieved using water activation. This was clearly demonstrated by the reduced annual steam consumption data from the office building.

In yet to be published data, continuing improvement in another heat exchanger was observed for several months after the removal of Kiko cartridges. Based on laboratory data, the probable explanation is that once water is sufficiently activated, it can begin to absorb KELEA from the environment leading to its further activation.

The transfer of heat from hot to cold fluids is widely utilized in many modern technologies [24] [25]. The two novel examples provided in this paper are only a beginning of the many systems, which need to be explored using Kiko Technology and other methods of water activation. The studies also provide a strong incentive to pursue the nature of KELEA and its detailed effects on water. 


\section{Summary}

Activation of water, as defined by its enhanced kinetic activity, has previously been proven to have agricultural and health benefits. This paper indicates that activated water can also have major industrial benefits. The focus of the present paper has been on the greater efficiency of heat transfer in a refrigeration unit (chiller) and in the production of hot water in a heat exchanger. While in both systems, there were indications of reduced scale formation within the water carrying metal pipes; the major effect is more consistent with the enhanced ability of activated water to more quickly absorb heat. Activation of water can result in substantial fuel savings.

\section{Acknowledgements}

James T. Osugi, President of Kiko Technologies and Joel Russell, Wayne Addison and Jeff Addison of Kiko Water Systems, Ltd., kindly shared data included in this publication.

\section{Conflict of Interest Statement}

The author has no direct financial involvement with Kiko Technology or any of its distributers. The Institute of Progressive Medicine is a component of MI Hope Inc., a non-profit public charity. It advocates the use of various methods of activating water for human, animal, agricultural and industrial uses.

\section{References}

[1] Stanford, H.W. (2012) HVAC Water Chillers and Cooling Towers: Fundamentals, Application, and Operation. 2nd Edition, CRC Press, Boca Raton, 374.

[2] Shah, R.K. and Sekulic, D.P. (2003) Fundamentals of Heat Exchanger Design. John Wiley \& Sons, Hoboken, 941. http://dx.doi.org/10.1002/9780470172605

[3] Lane, R.W. (1993) Control of Scale and Corrosion in Building Water Systems. McGraw-Hill, New York, 279.

[4] Crittenden, J.C., Trussell, R.R., Hand, D.W., Howe, K.J. and Tchobanoglous, G. (2012) MWH's Water Treatment: Principles and Design. 3rd Edition, John Wiley \& Sons, Hoboken, 1899. http://dx.doi.org/10.1002/9781118131473

[5] Quinn, C.J., Molden, T.C. and Sanderson, C.H. (1997) Magnetic Treatment of Water Prevents Mineral Build-Up. Iron and Steel Engineer, 74, 47-52.

[6] Brannagan, M. (2000) Magnetic Technology. In: Müller-Steinhagen, H., Ed., Handbook Heat Exchanger Fouling: Mitigation and Cleaning Technologies, Institution of Chemical Engineers, Rugby, 270-278.

[7] Kuivinen, D.E. (1975) Comparing Corrosion Rates of Steel Corrosion Coupons in Magnetically Treated Water and in a Water System Utilizing Corrosion Inhibitors. National Aeronautics and Space Administration, Lewis Research Center, Cleveland.

[8] Barrett, R. and Parsons, S.A. (1998) The Influence of Magnetic Fields on Calcium Carbonate Precipitation. Water Research, 32, 609-612. http://dx.doi.org/10.1016/S0043-1354(97)00277-7

[9] Baker, J.S. and Judd, S.J. (1996) Magnetic Amelioration of Scale Formation. Water Research, 30, 247-260. http://dx.doi.org/10.1016/0043-1354(95)00184-0

[10] Alimi, F., Tlili, M., Amor, M.B., Gabrielli, C. and Maurin, G. (2007) Influence of Magnetic Field on Calcium Carbonate Precipitation. Desalination, 206, 163-168. http://dx.doi.org/10.1016/j.desal.2006.02.064

[11] Baker, J.S., Judd, S.J. and Parsons, S.A. (1997) Antiscale Magnetic Pretreatment of Reverse Osmosis Feedwater. Desalination, 10, 151-166. http://dx.doi.org/10.1016/S0011-9164(97)00094-5

[12] Morse, D. (1990) Method and System for Variable Frequency Electromagnetic Water Treatment. US Patent No. $4,963,268$.

[13] Zhalko-Tytarenko, O., et al. (1996) Endogenous Electromagnetic Field Influence on the Free Energy of Hydrogen Bond Formation in Water. Proceedings of the 2nd Advanced Water Sciences Symposium, Dallas, 4-6 October 1996, $23-$ 27.

[14] Bennett, C.A. (2002) An Investigation into Electrostatic Water Treatment Systems. Ph.D. Theses and Dissertations, Lehigh University, Bethlehem, 757 p.

[15] Klepetsanis, P.G., Kladi, A., Ostvold, T., Kontoyiannis, C.G., Koutsoukos, P.G., Amjad, Z. and Reddy, M.M. (2002) The Inhibition of Calcium Carbonate in Aqueous Supersaturated Solutions, Spontaneous Precipitation and Seeded Crystal Growth. In: Amjad, Z., Ed., Advances in Crystal Growth Inhibition Technologies, Academic Plenum Publishers, New York, 123-137. http://dx.doi.org/10.1007/0-306-46924-3 9 
[16] Reddy, M.M. and Hoch, A.R. (2002) Calcite Crystal Growth Rate Inhibition by Aquatic Humic Substances. In: Amjad, Z., Ed., Advances in Crystal Growth Inhibition Technologies, Academic Plenum Publishers, New York, 107-121. http://dx.doi.org/10.1007/0-306-46924-3_8

[17] Cinar, S. and Beler-Baykal, B. (2005) Ion Exchange with Natural Zeolites: An Alternative for Water Softening? Water Science and Technology, 51, 71-77.

[18] Leung, T.K., Lin, S.L., Yang, T.S., Yang, J.C. and Lin, Y.S. (2014) The Influence of Ceramic Far-Infrared Ray (cFIR) Irradiation on Water Hydrogen Bonding and Its Related Chemo-Physical Properties. Hydrology: Current Research, 5, 3.

[19] http://www.fractalfield.com http://www.structuredwaterunit.com http://www.magneticeast.com/a_products.html http://www.viaqua.com

[20] http://www.granderwater.co.uk http://www.aquagenesisusa.com/howitworks.html

[21] Martin, W.J. (2015) KELEA Activated Water Leading to Improved Quantity \& Quality of Agricultural Crops. Advances in Plants \& Agriculture Research, 2, Article ID: 00033. http://dx.doi.org/10.15406/apar.2015.02.00033

[22] Martin, W.J. (2014) KELEA Activated Water-Enhancing the Alternative Cellular Energy (ACE) Pathway. In: Martin, W.J., Ed., Stealth Adapted Viruses; Alternative Cellular Energy (ACE) \& KELEA Activated Water, Random House, New York.

[23] Chaplin, M.F. (2010) Water’s Hydrogen Bond Strength. In: Lynden-Bell, R.M., Morris, S.C., Barrow, J.D., Finney, J.L. and Harper, C., Eds., Water and Life: The Unique Properties of $\mathrm{H}_{2} \mathrm{O}$, CRC Press, Boca Raton, 69-86. http://dx.doi.org/10.1201/EBK1439803561-c5

[24] Çengel, Y.A. and Ghajar, A.J. (2011) Heat and Mass Transfer: Fundamentals \& Applications. McGraw-Hill, New York, 924.

[25] Hagen, K.D. (1999) Heat Transfer with Applications. Prentice Hall, Englewood Cliff, 688. 